Botany Research Journal 6(1): 1-5, 2013

ISSN: 1995-4751

(C) Medwell Journals, 2013

\title{
Response of High Temperature Threat on the Physiological Characters of Alfalfa
}

\author{
Liu Da-Lin, Zhang Hua, Hu Kai-Qi, Cao Xi-Chun, Liu Zhao-Ming, Wang Kui and Yang Jun-Qiao \\ College of Animal Science and Technology, Yangzhou University, 225009 Yangzhou, China
}

\begin{abstract}
To explore the effect of the high temperature stress on the chlorophyll content and the conductivity in different alfalfa varieties, a field trial was conducted. Used SPAD-502 type chlorophyll analyzer to measure the chlorophyll SPAD in leaves, meanwhile determined relative conductivity and semilethal temperature and analyze. Results show that high temperature led to the decrease of chlorophyll content in different alfalfa varieties. The chlorophyll content of Leafy King, GL0602, Ameri Graze and Algonquin was significantly higher than that of Victoria, WL621, Flourish Age and Affinity. Through a relative conductivity calculated in 16 kinds of alfalfa breeds, semilethal temperature difference was obtained among the varieties. The findings indicated that Derby, Algonquin, Victoria and Affinity had poor comprehensive performances while Sidel, Alfalfa King and CUF101 had a stronger comprehensive performances. The results showed that Ameri Graze, Alfalfa King, Sitel and GL0602 had a less effect in high temperature stress of physiological changes index, showed strong heat resistance; however Victoria, Affinity, WL612 and Sanditi had a poor heat resistance.
\end{abstract}

$\underline{\text { Key words: Alfalfa, high temperature stress, chlorophyll content, relative conductivity, China }}$

\section{INTRODUCTION}

Alfalfa (Medicago sativa L.), a perennial forage legume has the most planting forage varieties across China and even in the world. Because of its good adaptability and high yield, good quality and other advantages, it is known as the best forage for feeding ruminant animal. Alfalfa has a cultural history of 2000 years in the country but in the past, the food and economic crops had been given priority to planted there was little attention paid to feed crops and thus the high quality forages were not widespread. In recent years with the improvement of living standard, dietary structure with more high-quality protein and nutrition balance has been widely pursued and the plant-eating livestock husbandry, together with high quality forage grass products have developed. However, in Huaihe river basin and areas North to Qinlin mountains, there are little alfalfa planting. The main reason is that these areas have high temperature in summer, too much rain and the acidic soil which are not suitable for alfalfa's growth. The development of alfalfa planting would effectively solve the fodder shortage in the south. Therefore, selection and breeding of alfalfa adaptative varieties of the southern climate are very urgent which would have important practical value and broad application prospect.

This research focused on the effect of high temperature stress on alfalfa chlorophyll content and electric conductivity and further evaluated the comprehensive effect of high temperature stress on the growth of alfalfa. The aim is to provide some references to heat resistance research in alfalfa.

\section{MATERIALS AND METHODS}

Materials and experimental design: About 16 kinds of alfalfa breeds were used as the experiment samples and planted in the experimental pots in Yangzhou University from November 2010 to October 2011. The soil in the experimental pots contains $1.2 \%$ organic objects, $0.12 \%$ full nitrogen, P 36.3 and $\mathrm{K} 88.7 \mathrm{mg} \mathrm{kg}^{-1}$. This experiment was made in complete random groups of different area that is 16 treatment and repeat for 3 times, 48 groups in total. The area of each group was $5 \times 4.5 \mathrm{~m}$ with 10 lines inside. The distance between lines was $40 \mathrm{~cm}$ and the sowing deep was $1.5-2 \mathrm{~cm}$. The width of the drainage ditch was $30 \mathrm{~cm}$ and there have protective line all around. Weeds were removed at times. The contrastive samples were planted in the soil from experimental pots. The fresh leaves were harvested at the different developmental stages for analysis. The leave samples were taken randomly and the 3rd complete leaf of the alfalfa was taken. In each group, it was repeated for 3 times and the leaves were put back in icebox to the lab and put in refrigerator at $-20^{\circ} \mathrm{C}$ for further uses.

These 16 breeds (Table 1) were provided by BARENBRUG except that GL0602 was provided by Institute of Grassland Science, Yangzhou University.

Corresponding Author: Liu Da-Lin, College of Animal Science and Technology, Yangzhou University, 225009 Yangzhou, China 
Table 1: The source and varieties (strains) of alfalfa in experiment

\begin{tabular}{llc}
\hline Variety & Fall dormancy & Germination rate (\%) \\
\hline Algonquin & 3 & 86.41 \\
Gold Empress & 3 & 88.02 \\
Ameri Graze & 4 & 88.88 \\
Leafy King & 4 & 90.96 \\
Affinity & 4 & 91.02 \\
Alfalfa King & 4 & 89.31 \\
Sitel & 5 & 90.63 \\
Sanditi & 5 & 90.69 \\
Derby & 5 & 91.56 \\
Victoria & 6 & 90.37 \\
Flourish Age & 8 & 90.26 \\
Sidel & 8 & 89.16 \\
Hunter River & 7 & 88.61 \\
CUF101 & 9 & 87.38 \\
WL612 & 9 & 91.47 \\
GL0602 & Unknow & 90.12 \\
\hline
\end{tabular}

Measurements of the indexes: The SPAD-502 type chlorophyll analyzer was used to measure the Chlorophyll SPAD value (Chl2SPAD). Relative conductivity was determined according to the method of Zhao and Li (2001) and calculated as the equatiom below calculating the relative conductivity:

$$
\text { Relative conductivity }=\frac{\text { Before boiling conductivity }}{\text { After boiling conductivity }}
$$

The determination of semilethal temperature was determined according to Zhao (2004).

Statistical analysis: The data were shown by Mean $\pm \mathrm{SD}$, basic processing with Microsoft Excel 2007 Software, results use the Software SPSS13.0 with one way ANOVA module variance analysis and significant inspection, multiple comparison with Duncan's Method.

\section{RESULTS}

Impact of high temperature threat on the concentration of chlorophyll in the leaves: The overall trend of chlorophyll content change in different alfalfa varieties under the Summer heat stress was consistent as the temperature increases, the content of chlorophyll gradually reduce.

It showed that high temperature stress caused the breakdown of the chlorophyll, induced leaf senescence, reduced the effective leaf area and destroyed the photosynthesis. Alfalfas' chlorophyll contents were highest in June. When the temperature was appropriate, 16 varieties were in a normal growth state. From June to August, different alfalfas' chlorophyll contents decreased with difference, reflecting the various varieties under high temperature stress had different resilience. When temperature dropped down, alfalfa began to recover to normal growth with the increase of chlorophyll content (Fig. 1). The order of monthly chlorophyll content reduction rate was: Leafy King (34.87\%) > GL0602 (30.64\%) $>$ Ameri Graze (29.52\%) >Algonquin (28.94\%) > Gold Empress $(26.59 \%)>\operatorname{Sitel}(25.85 \%)>$ Alfalfa King $(23.28 \%)$ $>$ Derby $(23.02 \%)>$ CUF101(18.61\%) > Hunter River $(18.48 \%)>$ Sidel $(18.41 \%)>$ Sanditi $(17.54 \%)>$ Affinity $(15.18 \%)>$ Flourish Age $(14.38 \%)>$ WL612 (13.98\%) $>$ Victoria (12.04\%). The order reflected that chlorophyll content changed faster indicated the heat resistance was poorer (Fig. 1).

The relationship between different temperature treatments and relative conductivity: Under the high temperature stress, plasma membrane was the interface and barriers between living cells and the environment, bad environmental factors affected the plasma membrane which made electrolytes out from cell thus caused the subsequent increase of organization leaching solution electrolyte concentration subsequently heighten and relative electric conductivity. Under high temperature stress part of the electrolyte in cells was extravasated which made conductivity of solution increased.

Under the stress of high temperature, the alfalfa's leaves cell membrane permeability increased that lead to an increase of electrolyte leaving but there were differences under different temperature stress (Fig. 2).

By calculating $16 \mathrm{kinds}$ of alfalfa varieties relative conductivity of different temperature treatment, various varieties all presented a typical $S$ shape change trendency. The relative conductivity slowly increased with temperature in the range of $30-40^{\circ} \mathrm{C}$, rapidly increased with temperature in the range of $45-55^{\circ} \mathrm{C}$ and at last slowly increased. However, the amplitudes of the leaves' relative conductivity were also different in these different varieties. When the temperature changed from $45-55^{\circ} \mathrm{C}$, the sequence was Derby $(92.24 \%)>$ Algonquin $(84.55 \%)$ $>$ Victoria $(84.28 \%)>$ Affinity $(73.58 \%)>$ WL612 $(69.64 \%)$ $>$ Leafy King $(65.86 \%)>$ Sanditi $(65.58 \%)>$ Gold Empress $(65.22 \%)>$ Flourish Age $(59.37 \%)>$ Hunter River $(58.19 \%)$ $>$ GL0602 (57.04\%) > Sitel (56.61\%) >CUF101 (54.27\%) $>$ Alfalfa King (51.35\%) > Ameri Graze (48.95\%) > Sidel (38.98\%) (Fig. 2). The results reflected that the more the relative electric conductivity increased, the worse the resistance was.

Logistic equation and the determination of semilethal temperature: There is a self sustaining temperature range in the plant growth process, plants can go on normal metabolism and not get hurt in this temperature limits. In the high temperature conditions, plants can adjust themselves to adapting to the environment temperature in a certain period. Under high temperature stress, leaves cells relatively electric conductivity increases with temperature rising. But the relationship between them is not linear. When the relation between the relative electric 
Bot. Res. J., 6(1): 1-5, 2013

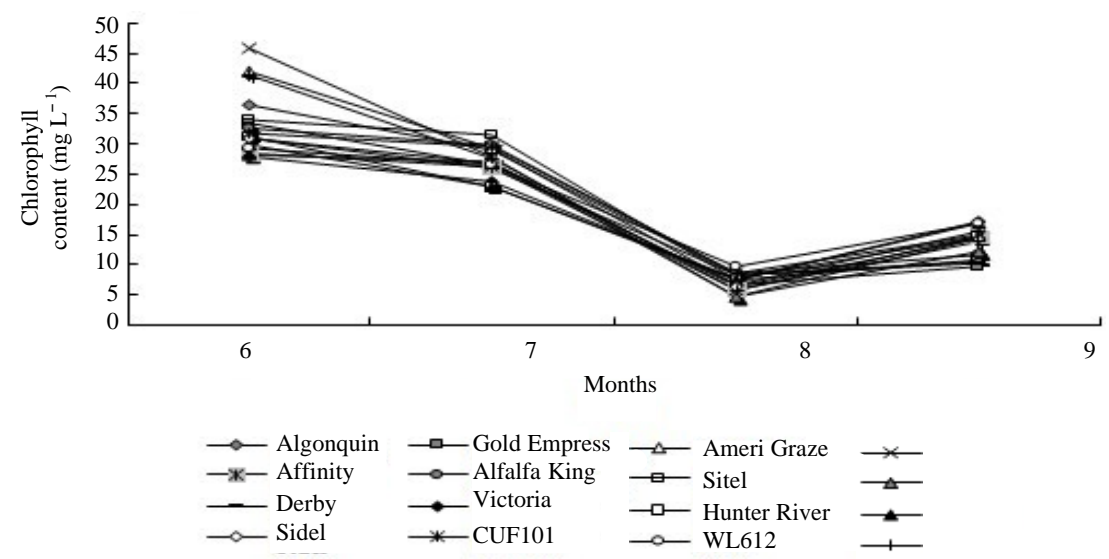

Fig. 1: The curve of the chlorophyll content on different months of different alfalfa varieties (strains)

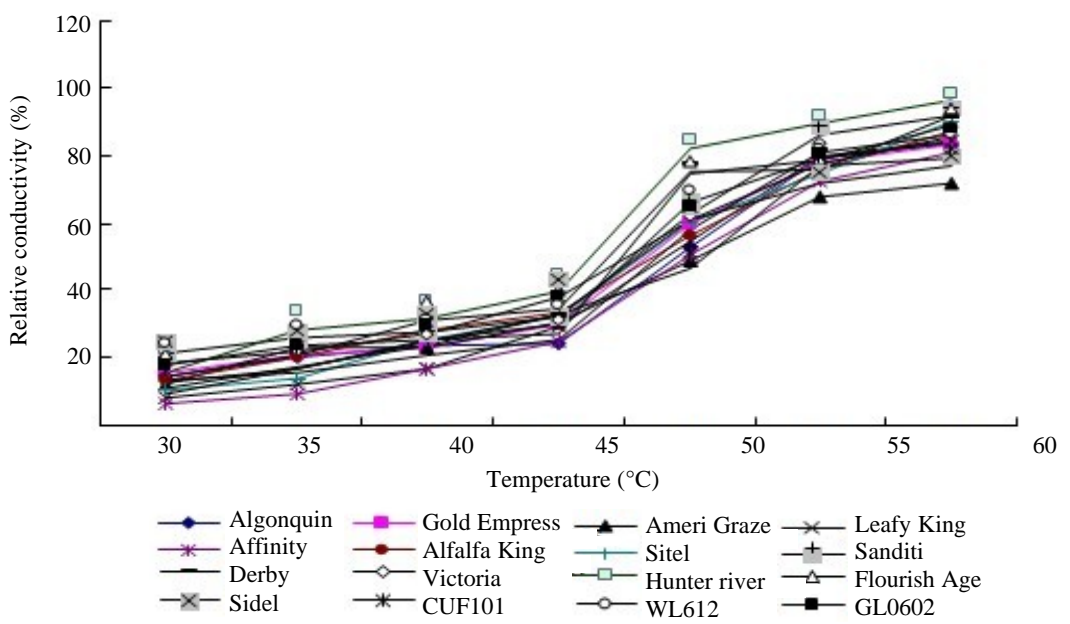

Fig. 2: The relative conductivity of alfalfa at different temperatures

conductivity and temperature shows $\mathrm{S}$ curve and the curve and Logistic equation have better fitting degree, it can seek the inflection point temperature in this point high temperature on electrolyte leakage percentage give the largest effect.

The test results show that various varieties (strains) detached leaves in $30 \mathrm{~min}$ heat treatment process, the membrane permeability changes with the different processing temperature. The membrane permeability is gently rising from $30-45^{\circ} \mathrm{C}$ temperature range and differences among different varieties are not too much. The membrane permeability increases greatly temperature from $45-60^{\circ} \mathrm{C}$ at the same time the differences among different varieties increase. The grass seed's membrane permeability curve is $\mathrm{S}$ model which fitting to Logistic equation. In order to ascertain the semilethal temperature, researchers calculate the inflection point temperature, the $\mathrm{LT}_{50}$ values of 16 alfalfa varieties (strains) are in the range of $48.38-55.35^{\circ} \mathrm{C}$ and the average is $49.47^{\circ} \mathrm{C}$ (Table 2).
Table 2: The different varieties (strains) Logistic equation and the inflexion temperature

\begin{tabular}{|c|c|c|c|}
\hline Varieties & Logistic equation & $\begin{array}{c}\text { Inflexion } \\
\text { temperature }\end{array}$ & $\mathrm{R}^{2}$ \\
\hline Algonquin & $\mathrm{y}=(95.19 / 1+6341.13) \mathrm{e}^{-0.175 \mathrm{x}}$ & 50.03 & 0.982 \\
\hline Gold Empress & $\mathrm{y}=(96.78 / 1+5982.52) \mathrm{e}^{-0.178 x}$ & 48.86 & 0.972 \\
\hline Ameri Graze & $\mathrm{y}=(90.14 / 1+959.04) \mathrm{e}^{-0.139 \mathrm{x}}$ & 49.40 & 0.986 \\
\hline Leafy King & $\mathrm{y}=(92.69 / 1+56396.22) \mathrm{e}^{-0.225 \mathrm{x}}$ & 48.62 & 0.993 \\
\hline Affinity & $\mathrm{y}=(91.29 / 1+15760.751) \mathrm{e}^{-0.193 \mathrm{x}}$ & 50.08 & 0.995 \\
\hline Alfalfa King & $\mathrm{y}=(97.02 / 1+982.58) \mathrm{e}^{-0.133 \mathrm{x}}$ & 51.81 & 0.991 \\
\hline Sitel & $\mathrm{y}=(98.21 / 1+2440.67) \mathrm{e}^{-0.156 \mathrm{x}}$ & 50.00 & 0.991 \\
\hline Sanditi & $\mathrm{y}=(93.91 / 1+583.81) \mathrm{e}^{-0.125 \mathrm{x}}$ & 50.96 & 0.985 \\
\hline Derby & $\mathrm{y}=(92.01 / 1+68970.93) \mathrm{e}^{-0.233 \mathrm{x}}$ & 47.82 & 0.994 \\
\hline Victoria & $y=(90.51 / 1+5199.01) \mathrm{e}^{-0.175 x}$ & 48.89 & 0.990 \\
\hline Hunter River & $\mathrm{y}=(92.46 / 1+1911.87) \mathrm{e}^{-.162 \mathrm{x}}$ & 46.64 & 0.951 \\
\hline Flourish Age & $\mathrm{y}=(91.54 / 1+29695.92) \mathrm{e}^{-0.224 \mathrm{x}}$ & 45.98 & 0.974 \\
\hline Sidel & $\mathrm{y}=(92.53 / 1+492.34) \mathrm{e}^{-0.112 \mathrm{x}}$ & 55.35 & 0.968 \\
\hline CUF101 & $\mathrm{y}=(98.73 / 1+2472.34) \mathrm{e}^{-0.156 \mathrm{x}}$ & 50.08 & 0.973 \\
\hline WL612 & $\mathrm{y}=(92.23 / 1+1286.51) \mathrm{e}^{-0.148 x}$ & 48.38 & 0.951 \\
\hline GL0602 & $\mathrm{y}=(91.34 / 1+1872.98) \mathrm{e}^{-0.155 \mathrm{x}}$ & 48.61 & 0.982 \\
\hline
\end{tabular}

$\mathrm{LT}_{50}$ can distinguish the heat resistance among different varieties (strains), varieties (strains) in high $\mathrm{LT}_{50}$ 
have better heat resistance. The experimental results show that Sidel has the strongest heat resistance, followed by the Alfalfa King, Sanditi, Affinity, CUF101, Algonquin and Sitel.

\section{DISCUSSION}

Chloroplasts are the photosynthesis organelles. Under high temperature stress, the plant growth will be seriously affected because of its damage. High temperature can cause the degradation of chlorophyll and affects $\mathrm{CO}_{2}$ solubility, reduces the affinity of 1,5-ribulose bisphosphate carboxylase to $\mathrm{CO}_{2}$ and key components of thermal stability of photosynthetic system which finally interferes with the plant photosynthesis (Ladjal et al., 2000). From the point of heat resistance, under the heat stress the heat-resistant varieties could maintain a relatively high chlorophyll content and keep a good photosynthetic potential. The degradation of chloroplasts speed up and the chlorophyll content is low in non heat-resistant varieties and photosynthesis drop down (Ma et al., 2004).

In many cell functions which is inhibited by high temperature, photosynthesis get most sensitively affected under the high temperature stress and the net photosynthetic rate decreases with the temperature rise. High temperature can change the thylakoid membrane structure as high temperature can improve the thylakoid membrane for the proton traversing performances, improve the electronic transfer around PSI. Sharkey (2005) reported that at temperature of $30-42^{\circ} \mathrm{C}$, photosynthetic carbon assimilation process was affected in plants and the enzyme activity of Rubisco was reduced, the function of PSI, cell pigment complex and thylakoid membranes were also affected. Considerable evidences have indicated that adversity can lead to plant in the accumulation of $\mathrm{O}^{2-}$ thus make a direct result of the destruction of chlorophyll especially the specific destruction of chlorophyll a, leading to the breakdown of chlorophyll and decrease the proportion of chlorophyll $\mathrm{a} / \mathrm{b}$.

Several measurements were conducted in the study, including total content of chlorophyll from June to September. The chlorophyll content of Leafy King, Sanditi, Affinity, Victoria relatively had little change, showing a good heat resistance. Liu (2005), Chen and Liu (1997) and their colleagues also reported that under high temperature stress, plants had significantly lower chlorophyll content and reflected differences among varieties. Under high temperature stress, the decline speed of the chlorophyll content in heat resistance strong plant species and varieties was slower than heat resistance weak and slow and had set up a file in the wheaton get application (Vierling and Nguyen, 1992). Zhang et al. (2006) reported that high temperature stress caused a lower chlorophyll content in festuca and chlorophyll was damaged which affected the photosynthesis and destroyed nutritional supply in alfalfa, thus affected the metabolism of the plant.

\section{CONCLUSION}

As expected, high temperature led to a decrease in chlorophyll content in different alfalfa varieties (12.04-34.87\%). The chlorophyll content of Leafy King, GL0602, Ameri Graze and Algonquin was significantly higher than that of Victoria, WL621, Flourish Age and Affinity $(p<0.05)$. Through, a relative conductivity and cell damage rate calculated in 16 alfalfa breeds, membrane permeability and semilethal temperature difference were obtained among the varieties. The findings indicated that Derby, Algonquin, Victoria and Affinity had poor comprehensive performances while Sidel, Alfalfa King and CUF101 had a stronger comprehensive performances.

Conclusion demonstrated that high temperature stress on the chlorophyll content and the conductivity in different alfalfa varieties had great differences. All the analysis showed that Ameri Graze, Alfalfa King, Sitel and GL0602 had a less effect in high temperature stress of physiological changes index, showed strong heat resistance while Victoria, Affinity, WL612, Sanditi had a poor heat resistance.

\section{ACKNOWLEDGEMENT}

This research was supported by Science and Technology Support Plan (Agriculture) project, Jiangsu, 2010 (E2010308).

\section{REFERENCES}

Chen, L.S. and X.H. Liu, 1997. High temperature stress on the peach and shaddock cell membrane permeability and the influence of photosynthetic pigment. J. Wuhan Botanical Res., 15: 233-237.

Ladjal, M., D. Epron and M. Ducrey, 2000. Effects of drought preconditioning on thermo tolerance of photosystem II and susceptibility of photosynthesis to heat stress in cider seedling. Tree Physiol., 20: 1235-1241.

Liu, M.X., 2005. Preliminary study of production performance and ecological adaptability of 12 alfalfa varieties in hot and humid area in southwest Sichuan. Sichuan Agricultural University, 5. 
Ma, X., H. Peng, M. Wang, L. Wang and Q. Sun, 2004. Evaluation of crops heat resistant. Chin. Bull. Bot., 21: $411-418$

Sharkey, T.D., 2005. Effects of moderate heat stress on photosynthesis: Importance of thylakoid reactions, Rubisco deactivation, reactive oxygen species and thermotolerance provided by isoprene. Plant Cell Environ., 28: 269-277.

Vierling, R. and H. Nguyen, 1992. Heat shock protein gene expression in diploid wheat genotypes differing in thermal tolerance. Crop Sci., 32: 370-337.
Zhang, Q.F., S. Xu and J.L. Li, 2006. A study on variations of physiological and biochemical indices of high temperature stress in Festuca arundinacea cv. Barlexas. Pratacult. Sci., 23: 26-28.

Zhao, X. and Y.L. Li, 2001. Indexes of high temperature stress on a few physiological variation characteristics of cold lawn grass. Pratacult. Sci., 10: 85-91.

Zhao, Y.H., 2004. Measuring the heat resistance of cold-season turfgrass by applying logistic equation. Hubei Agric. Sci., 12: 108-110. 